\title{
A Teoria da Aprendizagem Significativa e o Clube de Ciências: análise de uma sequência didática para o ensino de Citologia
}

\author{
Lucileine Basgal $^{1} \&$ Juliane Marques-de-Souza ${ }^{1,2}$
}

1. Universidade Estadual de Roraima. Rua 7 de Setembro, 231, Canarinho. Boa Vista/RR. CEP: 69306-530.

2. Programa de Pós Graduação em Ensino de Ciências e Matemática (PPGEC)/Universidade Estadual de Roraima (UERR). Rua 7 de Setembro, 231, Canarinho. Boa Vista/RR. CEP: 69306-530.

E-mail para contato: juliane.marques.souza@gmail.com

Recebido em : 31/10/2015. Aceito em: 21/12/2015. Publicado PDF em: 30/12/2015

\section{RESUMO}

\begin{abstract}
A teoria da aprendizagem significativa e o clube de ciências: análise de uma sequência didática para o ensino de citologia. Este artigo resulta de um processo de pesquisa cujo objetivo geral foi analisar o processo de ensino-aprendizagem de citologia desenvolvido no âmbito do Clube de Ciências tendo-se como base a Teoria da Aprendizagem Significativa de David Ausubel. Para tanto objetivou-se identificar os subsunçores para citologia dos alunos participantes do Clube de Ciências; elaborar atividades didáticas tendo como base a análise prévia dos subsunçores; E, por fim, avaliar o processo de aquisição de significados a partir de materiais e estratégias diferenciadas desenvolvidas no Clube de Ciências. A pesquisa foi realizada em uma Escola Estadual de Ensino Médio do município de Mucajaí, Roraima. A coleta e análise dos subsunçores foram realizadas a partir de uma mídia interativa desenvolvida pelos mestrandos do Mestrado Profissional em Ensino de Ciências da Universidade Estadual de Roraima. A sequência didática consistiu na construção de modelos celulares, aulas com microscópio, aulas de campo, confecção de lâminas, filme e jogos. A técnica de avaliação utilizada se deu com a construção de mapa conceitual e com questionário avaliativo das atividades utilizadas no clube de ciências. Conforme os resultados do mapa conceitual e do questionário final evidenciou-se que, mesmo após um tempo da realização das atividades no clube, os conceitos estudados ainda eram lembrados pelos estudantes e esses, apresentavam-se mais elaborados e diferenciados do que aqueles apresentados na avaliação prévia.
\end{abstract}

PALAVRAS CHAVE: Clube de Ciências, Aprendizagem Significativa, Mapas conceituais.

\begin{abstract}
The Meaningful Learning Theory and Science Club: an analysis of the teaching and learning process of cytology concepts. This article results from a research process which objective was to analyze the teaching and learning process of cytology concepts developed under the Science Club. It was based on the Meaningful Learning Theory of David Ausubel. For that, it was aimed to identify subsumers to cytology of the students members of the Science Club; to develop educational activities based on the prior analysis of subsumers; And finally, to evaluate the acquisition of meanings mediated by different materials and strategies developed in the Science Club. The research was conducted in public High School in the city of Mucajaí, Roraima. The subsumers collection and analysis was carried out from an interactive media developed by the masters students of the Professional Masters in Science Education from the State University of Roraima. The didactic sequence consisted of the construction of cellular models, lessons with microscope, field classes, preparation of slides, film and games. The valuation technique used was the construction of conceptual map and questionnaire evaluation of the activities used in the Science Club. According to the results it was evident that even after a while carrying out the activities at the club, the concepts were still remembered by students and were seen to be more elaborate and differentiated than those presented in the prior evaluation.
\end{abstract}

KEY WORDS: Science Club, Meaningful Learning, conceptual maps.

\section{INTRODUÇ̃̃̃O}

O sistema de ensino brasileiro, bem como o modelo predominante nas escolas, têm sido há muito questionado quanto à sua efetiva capacidade de desenvolver um espaço de construção de conhecimento. Livros didáticos transformados em roteiros prontos os quais são, em muitos casos, rigorosamente seguidos pelos docentes, figuram entre as ferramentas de ensino mais comuns no espaço escolar. Essa aparente ineficiência parece se concretizar quando nos deparamos com os números mais atuais do IDEB (Índice de Desenvolvimento da Educação Básica), o qual, para as séries finais do ensino fundamental do estado de Roraima obteve a nota 3,7 no ano de 2013 , ficando não somente abaixo da média nacional $(4,2)$ como também abaixo da meta prevista para aquele ano ${ }^{1}$.

Nesse contexto, o Clube de Ciências tem sido apontado como um espaço democrático 
dentro do ambiente escolar, que busca resgatar a curiosidade, a criatividade e a aprendizagem conduzida pela indagação, pelo questionamento e pela pesquisa (Delizoicov 2007; Silva \& Borges 2009). O presente artigo, portanto, é parte de um projeto maior que buscou implantar um Clube de Ciências em uma escola pública no município de Mucajaí, Roraima, visando alimentar o interesse dos jovens do ensino médio pela ciência. Esse projeto foi financiado pelo PIBID (Programa de Iniciação à Docência), por meio de bolsas de estudo e materiais para execução das atividades.

Durante a execução das atividades no clube, sentiu-se a necessidade de estudar como se dá o processo de ensino e aprendizagem de estudantes participantes do Clube de Ciências e de analisar a eficácia desse espaço de aprendizagem, fora do ambiente da sala de aula. Considerou-se nessa análise a potencialidade desses espaços ao trazer para os estudantes novas estratégias de ensino e motivação para adquirirem conhecimento.

O objetivo geral desse estudo foi, portanto, analisar o processo de ensino-aprendizagem de citologia desenvolvido no âmbito do Clube de Ciências tendo-se como base a Teoria da Aprendizagem Significativa de David Ausubel. E, os objetivos específicos foram: Identificar os subsunçores para citologia dos alunos participantes do Clube de Ciências; elaborar atividades didáticas tendo como base a análise prévia dos subsunçores e; avaliar processo de aquisição de significados a partir de materiais e estratégias diferenciadas no Clube de Ciências.

\section{A aprendizagem significativa}

A Teoria da Aprendizagem Significativa, proposta por David Ausubel, sugere que existam, pelo menos, dois tipos de aprendizagem. A aprendizagem significativa e a aprendizagem mecânica. Antunes (2001) afirma que essa última ocorre quando queremos aprender determinado assunto e ficamos repetindo até o cérebro registrar as informações selecionadas como relevantes, só que com o passar do tempo logo às esquecemos. $\mathrm{O}$ mesmo autor afirma que na aprendizagem significativa acontece o contrário, porque procuramos associar o assunto que se quer aprender com o que já sabemos, criando-se assim uma conexão e uma maior duração memorial desse conhecimento.

Segundo Moreira \& Masini (2001) quando não existe conhecimento prévio sobre determinado assunto, pode-se usar a aprendizagem mecânica até que esse conhecimento possa se tornar subsunçor. Os autores declaram que, à medida que a aprendizagem começa a se tornar significativa, esses subsunçores vão ficando cada vez mais elaborados e mais capazes de ancorar novas informações.

Logo, Guimarães (2009), Moreira \& Masini (2001) e Moreira (2010) corroboram dizendo que na aprendizagem significativa há uma interação entre o novo conhecimento e o já existente, na qual ambos se modificam. Vale destacar que o termo subsunçor é empregado na Teoria da Aprendizagem Significativa para referir-se ao conhecimento prévio existente na estrutura cognitiva do aprendiz (Moreira 2010).

Além deste conhecimento prévio, Pelizzari (2002) acrescenta que para haver aprendizagem significativa o aluno precisa ter disposição para aprender e o conteúdo a ser aprendido precisa ser lógico e psicologicamente significativo, porque se o aluno não estiver disposto a aprender o ensino se tornará mecânico. Nesta lógica, o conteúdo a ser trabalhado deverá ser bem elaborado e deve garantir a participação ativa e motivada dos estudantes.

$\mathrm{O}$ processo de aprendizagem, na teoria ausubeliana, passa pelos estágios de assimilação, retenção e de esquecimento (assimilação obliteradora), para só então se tornar significativa (Ausubel 2003). E se apresenta de três maneiras: aquela em que o conhecimento prévio é mais geral e inclusivo que o novo conhecimento (aprendizagem subordinada); aquela em que o conhecimento prévio é mais específico e menos abrangente (aprendizagem superordenada) e, por fim, a aprendizagem combinatória (Moreira \& Masini 2001).

Em qualquer uma das formas de aprendizagem, o papel do professor envolve pelo menos quatro etapas consideradas fundamentais, são elas: i) organizar hierarquicamente e progressivamente a estrutura conceitual e proposicional da matéria de ensino; ii) identificar os subsunçores relevantes à aprendizagem do conteúdo a ser ensinado; iii) diagnosticar o que o aluno já sabe para organizar a matéria de ensino; iv) e ensinar utilizando recursos e princípios que facilitem a aquisição da estrutura conceitual da matéria de ensino de uma maneira significativa (Moreira \& Masini 2001). É nesse momento, portanto, 
que o Clube de Ciências se apresenta como um espaço em potencial para a promoção da aprendizagem significativa.

\section{Clube de ciências}

Para Silva \& Borges (2009) os Clubes de Ciências proporcionam um ambiente diferenciado que possibilita atividades voltadas ao estudo, desenvolvimento de projetos, debates e discussões sobre temas que envolvem a ciência fora da sala de aula, tanto para alunos que participam como sócios, quanto para acadêmicos envolvidos com o espaço escolar em seu período de formação profissional.

Ainda nessa perspectiva, Delizoicov (2007) afirma que os Clubes de Ciências são espaços de divulgação científica e cultural e não podem estar desvinculados do processo de ensinoaprendizagem, mas devem fazer parte dele de forma planejada, sistemática e articulada. Para Borges \& Moraes (1998) o Clube de Ciências vem a colaborar com a formação das habilidades e competências desejáveis ao cidadão deste século, dentre as quais os autores destacam: a autonomia moral e intelectual do educando; o exercício da cidadania e; a produção do conhecimento por meio da pesquisa.

Segundo Barbiere (2002) é na própria escola que o aluno deve ter o seu "espaço científico" e esse deve ser orientado a aprender ciência, fazendo ciência, experimentando ideias, fazendo perguntas, redescobrindo o que já foi feito, criando novas ideias, tirando conclusões. Esse processo seguramente levará o estudante a continuar ou retroceder em seu interesse na área da ciência.

Vindo ao encontro com o exposto acima, onde o potencial pedagógico do Clube de Ciências é evidenciado, cabe destacar como o ensino de biologia enquadra-se neste contexto.

De acordo com Krasilchik (2004), os objetivos do ensino de biologia são aprender conceitos básicos, analisar o processo de pesquisa científica e analisar as implicações sociais da ciência. A autora comenta que a biologia pode ser uma das disciplinas mais relevantes e merecedoras da atenção dos alunos, ou uma das disciplinas mais insignificantes e pouco atraentes, dependendo da maneira que for ensinado e o que for ensinado.

Conforme os Parâmetros Curriculares Nacionais - PCNs (Brasil 2000) o objeto de estudo da Biologia é o fenômeno da vida em toda sua diversidade de manifestações, caracterizado por um conjunto de processos organizados e integrados, no nível de uma célula, de um indivíduo, ou ainda de organismos no seu meio. Nesta perspectiva, o Clube de Ciências pode contribuir para elevar o conhecimento dos alunos por meio de discussões e práticas, assim rendendo mais o seu aprendizado sobre ciência e biologia em sala de aula.

O Clube de Ciências vem ao encontro com as premissas teóricas da Teoria da Aprendizagem significativa, visto que os alunos são atores ativos em busca dos seus próprios conhecimentos, sem a obrigação de estar na sala de aula estudando determinado conteúdo porque depois serão avaliados com uma prova. No clube os estudantes têm a liberdade de escolher o que querem aprender, e de que maneira querem adquirir novos conhecimentos, partindo daquilo que já sabem.

Segundo Grein (2014, p.04)

\footnotetext{
Os alunos que participam de um Clube de Ciências, o fazem por sentirem-se atraídos pelas possibilidades oferecidas: de uma aprendizagem que permita construir e aprofundar conhecimentos, utilizando uma nova abordagem, com a realização de observações e manipulações em que se possa investigar, pesquisar e experimentar de uma maneira diferente das condições usuais de sala de aula.
}

Dentro do clube de ciências podem ser desenvolvidas algumas atividades para auxiliar o aprendizado dos alunos, como a produção de maquetes, jogos e a produção de lâminas para observação no microscópio. Acredita-se que essas atividades podem ser importantes aliadas do processo de aprendizagem significativa, mediando a inclusão do novo conhecimento à estrutura cognitiva do aprendiz.

\section{MATERIAL E MÉTODOS}

A abordagem dessa pesquisa foi qualitativa, pois segundo Martinelli (1999), a pesquisa qualitativa tem caráter inovador e se enquadra na busca de significados adquiridos pelos sujeitos às suas experiências adquiridas no decorrer da pesquisa.

O estudo foi realizado com um grupo de 06 (seis) alunos do $9^{\circ}$ ano de uma escola da rede estadual de ensino, no município de Mucajaí, 
Roraima. Os alunos participantes aceitaram voluntariamente participar do Clube de Ciências no contra turno do horário escolar.

Para dar conta dos objetivos a presente pesquisa organizou-se nas seguintes etapas:

$\mathrm{Na}$ primeira etapa foi feita a análise dos subsunçores utilizando uma atividade sobre biologia celular elaborada pelos alunos do Mestrado Profissionalizante em Ensino de Ciências da Universidade Estadual de Roraima (UERR) e que havia sido aplicada em escolas de Boa Vista. Trata-se de uma atividade interativa de perguntas e respostas e que utiliza como ferramenta de interação o computador. Os resultados obtidos foram analisados para, somente após a identificação dos subsunçores disponíveis, proceder-se com a elaboração do material de ensino.

$\mathrm{Na}$ segunda etapa foram organizados os materiais do processo de ensino-aprendizagem, que consistiu na construção de jogos, de protótipos das células, em aulas com microscópio, aulas de campo, na confecção de lâminas e outros. Assim, nessa etapa da teoria da aprendizagem significativa trabalhou-se a aquisição e a retenção do novo conhecimento.

$\mathrm{Na}$ terceira etapa foram aplicados mapas conceituais para avaliação da assimilação dos conteúdos após o esquecimento, pois segundo Moreira (2010) "na avaliação através de mapas conceituais a principal ideia é a de avaliar o que o aluno sabe em termos conceituais" sendo assim possível verificar os conceitos que esse aluno assimilou e que ficaram retidos na memória por um período de tempo maior.

Vale destacar que Moreira (2010) apresenta os mapas conceituais como diagramas de significados que indicam relações entre conceitos, e/ou entre palavras que são usadas para representar conceitos, que apresentam relações significativas e hierarquias conceituais.
$\mathrm{Na}$ última etapa foi aplicado um pequeno questionário opinativo com perguntas avaliativas sobre as atividades trabalhadas no clube.

A avaliação do Mapa Conceitual foi realizada de acordo com os critérios do quadro 1 definidos por Novak \& Gowin (1984). Foram avaliados aspectos como: as relações que ligam os conceitos observando a presença e ausência de palavras de ligação; a organização da hierarquia dos conceitos e as ligações cruzadas existentes nas relações entre os seguimentos da hierarquia dos conceitos. Para cada um desses itens foi atribuído um valor acompanhado de um peso específico. Após a realização do cálculo de cada aspecto avaliado foi efetuada a soma desses valores para obtenção do total de pontos alcançado pelo aluno.

\section{RESULTADOS E DISCUSSÃO}

A pesquisa consistiu no desenvolvimento de uma sequência didática com os estudantes participantes do clube de ciências, onde o enfoque das atividades foi o estudo das células. As atividades desenvolvidas e os resultados obtidos são apresentados e discutidos a seguir.

\section{A criação do Clube de Ciências na escola}

As atividades no Clube de Ciências tiveram início com uma divulgação massiva do projeto e a inscrição dos estudantes interessados. No grupo destinado ao estudo de citologia inscreveram-se 25 estudantes. Apenas seis compareceram à primeira reunião.

Nesta oportunidade realizou-se uma breve explicação, porém mais detalhada, sobre o que se tratava o Clube de Ciências e sobre o tema que seria objeto de estudo dos alunos no clube. Decidiu-se, juntamente com os alunos, que o grupo se encontraria duas vezes por semana,

Quadro 1. Aspectos avaliativos do mapa conceitual (relações, hierarquia, ligações cruzadas) utilizada como base pela pesquisadora do projeto para avaliação dos mapas produzidos pelos estudantes. A pontuação difere nos aspectos avaliativos considerados significativos ou não e com presença e ausência de palavras de ligação. Quadro adaptado de Freitas (2011).

\begin{tabular}{|l|l|c|}
\hline \multicolumn{2}{|c|}{ ASPECTOS AVALIATIVOS } & PONTOS \\
\hline \multirow{2}{*}{ 1.RELAÇÕES } & Com palavras de ligação & 2 \\
\cline { 2 - 3 } & Sem palavras de ligação & 1 \\
\hline 2.HIERARQUIA & & 5 \\
\hline \multirow{3}{*}{ 3.LIGAÇÕES CRUZADAS } & Significativa & 10 \\
\cline { 2 - 3 } & Não significativa & 2 \\
\cline { 2 - 3 } & Criativa & 15 \\
\hline
\end{tabular}


nas terças e quartas-feiras no horário das 16:00h. Essa escolha justificou-se pelo fato dos alunos participarem de outro projeto na escola, todos os dias da semana no período oposto às aulas. Como primeira ação do clube foi acordado que todos compareceriam para um mutirão de limpeza e revitalização do laboratório de ciências. Este laboratório foi cedido pela escola para a realização das atividades do Clube de Ciências. Segundo Martins (2015), o objetivo do mutirão é mostrar que a escola não é apenas do gestor, professor e demais equipe, mas é do aluno e de toda a comunidade.

Tratando-se do laboratório de ciências, só assim foi possível transformar o ambiente, antes usado como depósito, sem cumprir sua função no processo de ensino-aprendizagem. Após o mutirão, o laboratório voltou a estar disponível não somente para os alunos do clube, mas para toda a escola e comunidade.

Após o início das atividades descobriu-se que a escola possuía dois microscópios e muitos materiais propícios para serem utilizados no laboratório, vários modelos anatômicos do corpo humano estavam encaixotados e guardados no "depósito".

O laboratório de ciências assume importante papel na condução do processo de ensino e aprendizagem porque é um ambiente onde o professor pode associar teoria e prática. Segundo Maluf (2007, p.24) o laboratório de ciências é:

Um espaço único para aulas de Biologia, trata-se de um recurso de grande sucesso para aprendizagem, pois é possível demonstrar determinado assunto visto na prática e também, de modo muito interessante e produtivo, iniciar e/ou finalizar um certo conteúdo no próprio laboratório.

Porém conforme Godefroid (2010) para o aluno atingir um bom desenvolvimento do processo de teoria e prática é necessário que o laboratório possua "uma boa estrutura", como por exemplo, uma boa iluminação e ventilação, que tenham bancadas, pias, vidrarias etc.

Conforme Felício (2013, p.07) destaca, "os laboratórios de muitas escolas, estão em desuso", fazendo com que esse espaço tenha sua importância diminuída perante as demais instalações escolares, "servindo então de depósito ou almoxarifado", privando os alunos de uma parte muito importante do processo de ensino e aprendizado, a experimentação. Felício (2013, p.07) também afirma que:
[...] a reativação dos laboratórios das escolas devolve à comunidade escolar um espaço destinado ao aprendizado, o qual nunca deveria ter sido "desativado", mesmo que temporariamente.

Uma vez superados esses obstáculos, foram iniciadas as atividades do clube de ciências, com a análise dos subsunçores.

\section{A análise do conhecimento prévio: os subsunçores existentes.}

Conforme mencionado anteriormente, de acordo com Moreira \& Masini (2001, p.19) os subsunçores são os conhecimentos prévios que as crianças adquirem ao longo da vida e que "à medida que a aprendizagem começa a ser significativa, os subsunçores vão ficando cada vez mais elaborados e mais capazes de ancorar mais informações".

A ferramenta utilizada para avaliar os respectivos conhecimentos prévios foi um software criado pelos alunos do mestrado da Universidade Estadual de Roraima, o qual continha duas atividades distintas. A ferramenta foi aplicada no laboratório de informática da escola, com os seis alunos que compareceram ao encontro, os quais responderam a atividade a qual foi analisada posteriormente. Ao final da atividade, os estudantes foram questionados a respeito das perguntas contidas na atividade e mencionaram que as acharam bem difíceis.

Como resultado, foi possível verificar que os alunos tinham um conhecimento restrito em relação à Citologia, isso ficou notório diante do percentual de acertos das questões, como mostra o quadro 2 .

$\mathrm{O}$ quadro 2 mostra que os alunos erraram mais as questões sobre a atividade 2 a qual solicitava que os estudantes fizessem a relação entre as organelas celulares e suas funções na célula eucarionte animal. Das oito questões, o maior número de acertos foi de um aluno que acertou três, enquanto os demais acertaram apenas duas questões.

Atividade 1, que continha variadas perguntas sobre os diferentes tipos de células e suas estruturas, os alunos acertaram mais. Das quatorze questões um aluno acertou nove, um oito e o restante acertou seis questões (Quadro 3), evidenciando a existência de mais subsunçores para temas mais gerais sobre as células, tais como: o tamanho de uma célula, a quantidade de células em um organismo etc. 
Quadro 2. Resultado da atividade diagnóstica aplicada para verificação dos subsunçores disponíveis na estrutura cognitiva dos estudantes participantes do projeto "Citologia" do Clube de Ciências da E.E. Padre José Monticone.

\begin{tabular}{|c|l|c|c|c|}
\hline ALUNO & \multicolumn{1}{|c|}{ ATIVIDADES } & QUESTÕES & ACERTOS & PERCENTUAL \\
\hline \multirow{2}{*}{1} & Atividade 1 & 14 & 6 & $43 \%$ \\
\cline { 2 - 5 } & Atividade 2 & 8 & 3 & $38 \%$ \\
\hline \multirow{2}{*}{2} & Atividade 1 & 14 & 8 & $58 \%$ \\
\cline { 2 - 5 } & Atividade 2 & 8 & 2 & $25 \%$ \\
\hline \multirow{3}{*}{3} & Atividade 1 & 14 & 6 & $43 \%$ \\
\cline { 2 - 5 } & Atividade 2 & 14 & 2 & $25 \%$ \\
\hline \multirow{2}{*}{4} & Atividade 1 & 8 & 2 & $43 \%$ \\
\cline { 2 - 5 } & Atividade 2 & 14 & 9 & $25 \%$ \\
\hline \multirow{2}{*}{5} & Atividade 1 & 8 & 2 & $64 \%$ \\
\cline { 2 - 5 } & Atividade 2 & 14 & 6 & $25 \%$ \\
\hline \multirow{2}{*}{6} & Atividade 1 & 8 & 2 & $43 \%$ \\
\cline { 2 - 5 } & Atividade 2 & & $25 \%$ \\
\hline
\end{tabular}

Dentre as questões com maior índice de erro na atividade 1 estão a de número 4 e a de número 6 (Quadro 3). Ambas eram perguntas simples sobre observar o desenho e apontar qual célula é eucarionte e procarionte e; apontar o nome da substância que preenche o citoplasma. Sabia-se, contudo, na ocasião da aplicação da atividade que esse era um conteúdo já estudado nas séries anteriores.

Vale aqui destacar que as questões 9 à 14 da Atividade 1 são consideradas mais complexas. $\mathrm{Na}$ questão 13, por exemplo, perguntou-se sobre a quantidade de cromossomos nas células humanas, no espermatozoide e no zigoto e, na questão 14, perguntou-se sobre as fases da mitose. Pelo conteúdo apresentado nessa parte da atividade já eram esperados tantos erros, visto que os alunos ainda não haviam estudado detalhadamente esse assunto (Quadro 3).

Conforme já mencionado, na atividade 2 havia uma célula eucarionte animal e as perguntas estavam relacionadas somente às organelas e suas funções, onde os alunos visualizavam a figura da célula com setas apontando a organela numerada e ao lado a função. Assim respectivamente eles deveriam associar a organela com a função. $O$ resultado dessa atividade está exposto no quadro 4.

Apesar da atividade 2 ter sido executada após a 1, não foi notado qualquer pressa ou falta de motivação por parte dos alunos em responder as questões. Sendo assim, uma explicação plausível para tantos erros é o fato dos alunos ainda não terem subsunçores para o conteúdo sobre as organelas e suas funções.

Ficou nítido que os alunos possuíam um conhecimento mais geral sobre o assunto de Citologia. Segundo Moreira \& Masini (2001) quando há um subsunçor mais geral e inclusivo, o tipo de aprendizagem que se adequa à realidade desses alunos é a aprendizagem subordinada.

Um ponto positivo expresso pelos estudantes foi que a atividade avaliativa não ocorreu como geralmente ocorre em uma aula em sala, com o professor explicando e apressando-os para terminarem logo a atividade antes do final da aula. Nesse sentido, Silva (2009) afirma que para os alunos entenderem melhor os conteúdos ministrados em sala de aula o professor necessita de um período maior de tempo, sendo que os conteúdos são passados de "forma muito rápida", tornando muito difícil a assimilação.

Segundo Santos (2008, p.08) o Clube de Ciências possibilita:

O desenvolvimento de atividades de interesse dos alunos por um determinado assunto científico despertado em aula, ou numa notícia, ou programa televisivo que chamou atenção, demanda tempo e instrumentos, nem sempre disponíveis em sala de aula. Essa necessidade pode ser suprida por um espaço de encontro e pesquisa, proporcionado pelo Clube de Ciências.

Tratando-se do tempo que o aluno tem para buscar o conhecimento, com certeza o Clube de Ciências é um espaço que proporciona um melhor aprendizado, devido não haver pressa em terminar o horário do encontro. 
Quadro 3. Resultado dos acertos e erros da atividade diagnóstica sobre a Atividade 1. Abreviações: T.Acertos: total de acertos; T.erros: total de erros.

\begin{tabular}{|c|c|c|c|c|c|c|c|c|}
\hline \multicolumn{9}{|c|}{ ATIVIDADE 1 } \\
\hline Questão & Aluno 1 & Aluno 2 & Aluno 3 & Aluno 4 & Aluno 5 & Aluno 6 & T. Acertos & T. Erros \\
\hline 1 & Certo & Certo & Certo & Certo & Certo & Certo & 6 & 0 \\
\hline 2 & Certo & Certo & Certo & Certo & Errado & Certo & 5 & 1 \\
\hline 3 & Certo & Certo & Errado & Certo & Certo & Errado & 4 & 2 \\
\hline 4 & Errado & Errado & Certo & Errado & Errado & Errado & 1 & 5 \\
\hline 5 & Certo & Certo & Certo & Errado & Errado & Errado & 3 & 3 \\
\hline 6 & Errado & Errado & Errado & Certo & Certo & Errado & 2 & 4 \\
\hline 7 & Certo & Certo & Certo & Errado & Certo & Certo & 5 & 1 \\
\hline 8 & Errado & Certo & Errado & Errado & Certo & Certo & 3 & 3 \\
\hline 9 & Errado & Certo & Errado & Certo & Errado & Errado & 2 & 4 \\
\hline 10 & Errado & Certo & Errado & Errado & Errado & Errado & 1 & 5 \\
\hline 11 & Errado & Errado & Certo & Errado & Certo & Certo & 3 & 3 \\
\hline 12 & Errado & Certo & Errado & Errado & Errado & Errado & 1 & 5 \\
\hline 13 & Certo & Errado & Certo & Certo & Errado & Errado & 3 & 3 \\
\hline 14 & Errado & Certo & Errado & Errado & Errado & Errado & 1 & 2 \\
\hline
\end{tabular}

Quadro 4. Resultado dos acertos e erros da atividade diagnóstica sobre a Atividade 2. Abreviações: T.Acertos: total de acertos; T.erros: total de erros.

\begin{tabular}{|c|c|c|c|c|c|c|c|c|}
\hline \multicolumn{9}{|c|}{ ATIVIDADE 2 } \\
\hline Questão & Aluno 1 & Aluno 2 & Aluno 3 & Aluno 4 & Aluno 5 & Aluno 6 & T. Acertos & T. Erros \\
\hline 1 & Certo & Certo & Certo & Certo & Certo & Certo & 6 & 0 \\
\hline 2 & Certo & Certo & Certo & Certo & Certo & Certo & 6 & 0 \\
\hline 3 & Errado & Errado & Errado & Errado & Errado & Errado & 0 & 6 \\
\hline 4 & Errado & Errado & Errado & Errado & Errado & Errado & 0 & 6 \\
\hline 5 & Errado & Errado & Errado & Errado & Errado & Errado & 0 & 6 \\
\hline 6 & Errado & Errado & Errado & Errado & Errado & Errado & 0 & 6 \\
\hline 7 & Certo & Errado & Errado & Errado & Errado & Errado & 1 & 5 \\
\hline 8 & Errado & Errado & Errado & Errado & Errado & Errado & 0 & 6 \\
\hline
\end{tabular}

Atividades voltadas para aprendizagem: aquisição e retenção de conceitos.

Segundo Moreira \& Masini (2001, p.20) a aquisição de conceitos "é a aquisição espontânea de ideias genéricas por meio da experiência empírica concreta". A aquisição de conceitos acontece por meio de atividades elaboradas voltadas para o conteúdo que se quer ensinar, que resultará na retenção de novos conceitos.

Para dar início a esta etapa da aprendizagem, foram passados dois vídeos retirados de um site na internet ${ }^{2}$, os quais tratavam do universo e iam até as células do nosso organismo. Os vídeos tinham como objetivo demonstrar a imensidão do universo comparado ao tamanho minúsculo de uma célula, porém tão importante para todos os seres vivos. Depois foi solicitado aos alunos a confecção de cartazes em cartolinas com o tema que mais tinha chamado

2. www.youtube.com.br/palidopontoazul e www.youtube.com.br/oquesaocelulas. Acessado em: 16/07/2014. 
a atenção dos mesmos (Figura 1 A).

Segundo Guimarães (2009, p.33)

Os filmes, nas suas diversas modalidades, constituem um recurso didático que permite aos educandos construir e modificar conceitos e visões de mundo. Além de facilitarem o processo de ensino-aprendizagem, tornando as aulas mais diversificadas e atraentes.

Guimarães (2009) destaca também a importância do uso dos cartazes para expor o que foi aprendido em relação a determinado assunto. Diz que "é uma excelente forma de organização de ideias por meio de uma linguagem não verbal" Guimarães (2009, p.34).

No encontro seguinte, foi aplicada uma atividade com um quebra-cabeça com o intuito de familiarizar esses alunos em relação às células. Os alunos montaram o jogo e visualizaram as organelas da célula animal (Figura 1 B). Foram também impressas em papel colorido e plastificado as organelas de cada tipo de célula. Com o material em mãos discutiu-se sobre cada tipo de organela e suas funções.

$\mathrm{Na}$ sequência das atividades, apresentou-se dois vídeos e um resumo onde descrevia as organelas e suas respectivas funções para ilustrar a tarefa seguinte do grupo. Solicitou-se então a elaboração de uma música descrevendo as organelas e suas funções na célula. Os estudantes, contudo, não aprovaram a ideia da composição da paródia, pois consideraram complicado achar uma música que se encaixasse no conteúdo em estudo.

Menezes (2012) destaca que o Clube de Ciências "têm a flexibilidade como característica" em suas propostas de atividades, assim direcionando a busca pelo conhecimento desses alunos conforme às suas necessidades e gostos. Isto é, se estes alunos não se sentirem motivados com as atividades, provalvelmente não poderão adquirir esse conhecimento.

Diante do exposto, com vista a dar início ao processo de retenção de conceitos, foi proposto que iniciassem a elaboração e criação de ferramentas didáticas. Além de beneficiar a aprendizagem dos mesmos, tinha-se a intenção de apresentá-las na próxima feira de ciências que haveria na escola. Para evitar a desmotivação anterior, foi deixado em aberto para que os próprios alunos escolhessem o que eles gostariam de produzir. Assim, decidiram que produziriam modelos da célula bacteriana, vegetal e animal respectivamente.

Antes de iniciar a elaboração dos modelos celulares foi elaborada uma atividade para observação celular em microscopia ótica, onde foi mostrado aos estudantes os micróscopios que a escola possui, dando uma breve explicação dos seus componentes e de como deveriam manuseá-lo com cuidado.

Esta atividade teve como objetivo demonstrar as diferenças de grandezas existentes entre as células animal e vegetal. Para tanto levou-se folhas de zebrina (Tradescantia zebrina Heynh) e cebolinha em palha (Allium schoenoprasum L.) para o laboratório, onde os próprios alunos prepararam as lâminas e as observaram no microscópio. Aproveitou-se a ocasião para ensiná-los a achar o foco no material em análise.

Na película da folha de zebrina foi possível observar a parede celular e na folha de cebolinha ficaram nítidos os cloroplastos. Aproveitou-se o mesmo encontro para mostrar algumas lâminas de células sanguíneas fornecidas pelo laboratorio da Universidade, onde foi possível observar algumas estruturas celulares, porém sem distingui-las.

Santos (2008) afirma que o ensino por meio da experimentação é quase uma necessidade no campo das ciências naturais, que deve haver um relacionamento estreito entre teoria e prática, onde o professor deverá em sala de aula aplicar a teoria sobre determinado assunto e posteriomente a prática preferencialmente em laboratório.

Retomando a ideia de produzir modelos das células em maquetes, após as atividades de observação em microscopia, seguiu-se à uma olaria às margens do Rio Mucajaí que doou argila para a produção da célula da bactéria. Aproveitou-se para coletar água em uma pequena lagoa nas proximidades com a intenção de em seguida observar organimos unicelulares no micróscopio do laboratório.

No laboratório foram montadas as lâminas, onde foi possível observar alguns organismos unicelulares em movimento (Figura $1 \mathrm{C}$ ). Destaca-se que o objetivo dessa atividade foi demonstrar a visualização dos organismos presentes na água que não são perceptiveis a olho nú, assim foi possível visualizá-los através do microscópio óptico.

No encontro seguinte iniciou-se a produção da célula da bactéria, onde foi usado barro tipo 


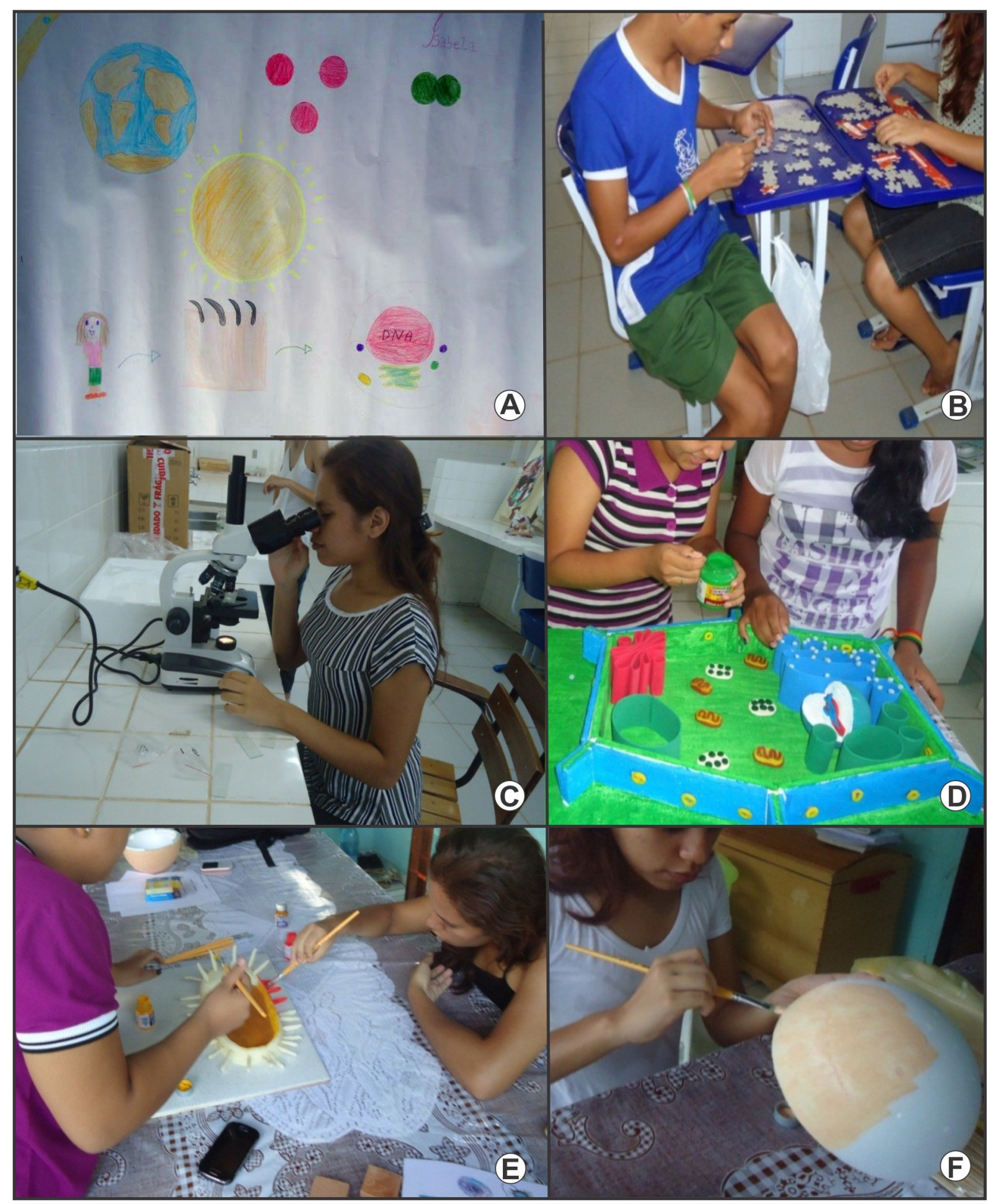

Figura 1. Atividades voltadas para a aprendizagem. A: Cartazes produzidos pelas alunas após assistirem um vídeo que fala sobre o universo e as células; B: Alunos do clube montando quebra cabeça com a imagem da célula animal e ao mesmo tempo visualizando as organelas que compõe a célula; $\mathbf{C}$ : Aluna visualizando os microrganismos na lâmina que ela mesma fez através do microscópio no laboratório de ciências da escola; D: Alunas montando a célula vegetal; E: Alunas pintando a célula da bactéria; F: aluna pintando a bola de isopor que serviu de suporte para as organelas da célula animal. 
argila, água e palitos. Estruturas, como cápsula, cílios e flagelos foram consideradas na elaboração do modelo. Porém, verificou-se que o resultado não foi bom, visto que a maquete rachou e se esfarelou. Tentou-se produzir esse tipo de maquete por três vezes porém nenhuma das vezes funcionou. Após as tentativas frustradas da produção da célula da bactéria com argila, houve a ideia de fazer com uma massa de biscuit, que é um material usado para confeccionar artesanato.

No decorrer do desenvolvimento das atividades do clube, a escola começou uma reforma e o laboratório voltou a ser tratado como depósito. A escola informou que não havia mais local disponível para o Clube de Ciências continuar com as atividades. Em virtude do exposto, algumas atividades passaram a ser desenvolvidas na casa da pesquisadora.

Tratando-se da importância do apoio da equipe escolar para o projeto desenvolvido na escola, Fernandes et al. (2014) ressaltam que o retorno da direção da escola é de extrema importância, pois fortalece a iniciativa e acarreta um certo status ao projeto do clube. Esse status certamente conduziria a uma ampliação dos membros do clube ao longo do tempo, bem como a uma consolidação do Clube de Ciências como um espaço de aprendizagem autônomo e diferenciado para os estudantes. A falta de apoio institucional, contudo, dificultou o amadurecimento esperado para as atividades do Clube de Ciências na escola.

Após a superação de problemas como o local de realização das atividades do clube, iniciou-se a confecção das organelas da célula vegetal (Figura $1 \mathrm{D}$ ), durante a elaboração dos modelos a estratégia adotada foi de sempre mostrar as figuras impressas e explicar as funções de cada uma das organelas.

Quando se trata sobre modelos, Brandão (2015) e Souza et al. (2004) comentam que os modelos biológicos como estruturas tridimensionais e coloridas são utilizadas como facilitadoras do aprendizado, pois além do lado visual, os modelos permitem que o aluno manipule o material, visualizando-o de vários ângulos, melhorando sua compreensão sobre o que está sendo estudado. Os modelos confeccionados permitem aos alunos relacionar teoria e prática com mais facilidade principalmente quando são modelos que eles mesmos estão construindo (Figuras $1 \mathrm{E}, \mathrm{F}$ ).
Santos (2010, p.2) menciona que "a construção e visualização de estruturas biológicas de maneira tridimensional podem facilitar o processo de ensino e aprendizagem". E segue afirmando que a utilização de modelos como material concreto no ensino de ciências é muito interessante porque promove uma criação de conhecimentos permanentes e que, com o passar do tempo, o aluno não esquecerá totalmente o que foi aprendido, tornando assim a aprendizagem significativa.

Os modelos elaborados foram expostos na Feira cultural, a qual ocorreu na praça do município. No decorrer da feira houve muita curiosidade sobre as maquetes (Figuras 2 A, B e C), principalmente da célula bacteriana, tanto dos alunos presentes como da comunidade em geral que foi prestigiar as exposições. Ficou evidente a satisfação das alunas em participar da feira expondo o trabalho que haviam passado semanas construindo com esforço e dedicação.

Segundo Guimarães (2009, p.80), as feiras são exposições de ciências que promovem educação, dentre os principais objetivos estão

\begin{abstract}
[...] Proporcionar experiências significativas no campo sociocientífico, nas quais os alunos tem a oportunidade de difundir conhecimentos científicos, intercambiar informações, desenvolver o comportamento social e fortalecer o vínculo entre a escola e a comunidade. Criar ambiente propício para o desenvolvimento da capacidade de trabalhar em equipe.
\end{abstract}

Segundo Santos (2008, p.10):

As Feiras de Ciências surgiram quase na mesma época e que sua principal função era mostrar o que se produzia ou reproduzia nos Clubes, ou seja, os frequentadores de Clubes de Ciências, provavelmente, participavam das Feiras de Ciências, apresentando o que haviam realizado nos encontros realizados nos Clubes.

Após a exposição dos modelos na feira, deuse continuidade com as atividades planejadas, seguindo-se para a elaboração do jogo da memória das organelas. (Figuras 2 D e E), foram feitas e impressas também as regras do jogo.

Tratando-se da produção do "Jogo da memória das organelas", como ferramenta para auxiliar na aprendizagem significativa, Fialho 


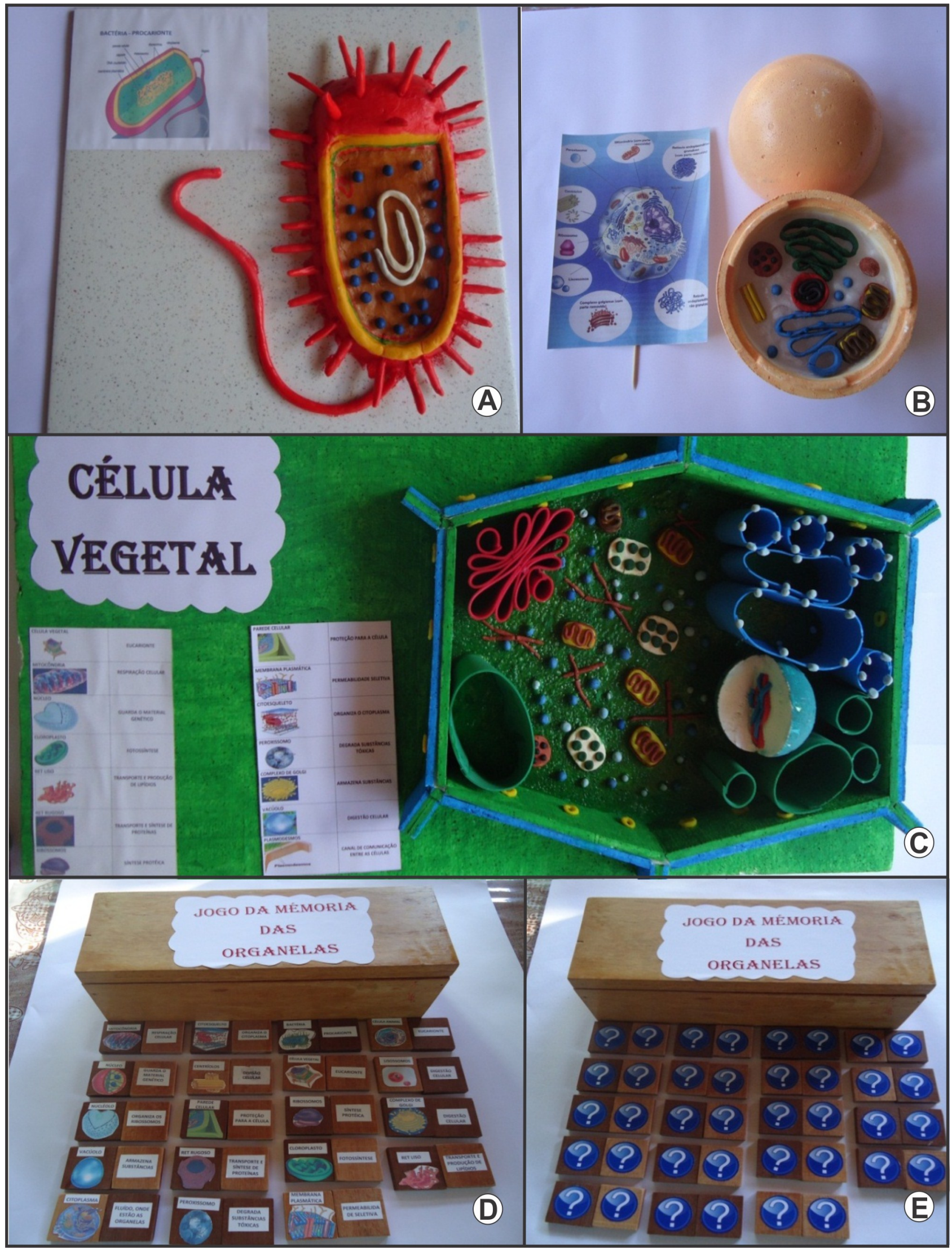

Figura 2. Modelos celulares e Jogo da Memória. A, Modelo pronto da célula da bactéria; B, modelo pronto da célula animal; C, Modelo pronto da célula vegetal; D e, Jogo da Memória das organelas frente e verso. 
(2007) destaca que o jogo serve de grande incentivo e muitas vezes de reforço para o aprendizado dos alunos, atuando como um instrumento extremamente interessante $\mathrm{e}$ motivador no ensino-aprendizagem.

Segundo Kishimoto (2002, p. 17) “o jogo aparece como algo sério e destinado a educar a criança", nesse sentido o jogo pode ser utilizado como ferramenta para ensinar os conteúdos aos alunos.

No encontro seguinte as alunas compareceram ao clube para jogar o "Jogo da Memória das organelas". Segundo Fialho (2007, p.130), "Para jogar, é necessário conhecer as regras, entendê-las e identificar o contexto em que elas são utilizadas a até inventar novas técnicas possíveis de serem aplicadas e adequadas às mesmas regras". Nesse sentido essa atividade foi muito importante pelo fato de que elas só acertariam os pares se conhecessem a organela e sua respectiva função.

Conforme Ward (2010) o uso dos jogos como ferramenta didática proporciona uma rica variedade de oportunidades de aprendizagem aos alunos e afirma mais, que "o jogo é conhecido como um poderoso mediador para a aprendizagem no decorrer da vida da pessoa" Ward (2010, p.162).

Tratando-se especificamente do jogo da memória, Ward (2010, p.168) declara que

$\mathrm{O}$ uso de jogos da memória pode aumentar a memória visual e a capacidade de fazer conexões. A memória não se encontra em apenas um lugar do cérebro, mas em todo ele, e pode ser aperfeiçoada com a prática. Pense na memória como um músculo, isto é, quanto mais é usada, melhor se torna.

No que se refere à Teoria da Aprendizagem Significativa, os jogos podem ser ferramentas potencialmente significativas para a aprendizagem, pois, são úteis para "facilitar a aprendizagem na medida em que funcione como pontes cognitivas" (Moreira \& Masini 2001, p.21).

\section{Avaliação da assimilação}

A última etapa dessa pesquisa consistiu na elaboração de mapas conceituais pelos alunos participantes do Clube de Ciências, especificamente do projeto de Citologia. Segundo Moreira (2010) os mapas conceituais servem como instrumentos para o professor avaliar os alunos, mas não somente avaliar no sentido de testar o conhecimento e atribuir nota ao aluno, mas pode ser usado também como instrumento para se conseguir informações sobre o tipo de assimilação que esse aluno obteve sobre o assunto estudado.

Moreira (2010) afirma ainda que os mapas conceituais não servem somente para avaliar a assimilação dos alunos de determinado conteúdo, mas servem também para promover uma aprendizagem significativa e de conceitualização, ou seja, antes desse aluno começar a fazer o seu mapa certamente ele irá pensar em quais conceitos e em que parte do mapa esse conceito ficará, tornando assim a confecção desse mapa uma forma de aprendizagem significativa e prazerosa.

Diante do exposto, foi utilizada como forma de avaliação a construção de um mapa conceitual, realizado pelos alunos individualmente. O mesmo foi aplicado de acordo com o conteúdo visto e com a orientação da pesquisadora desse projeto, os conceitos e as palavras de ligação para produção do referido mapa foram sugeridos pelos alunos.

Os mapas foram avaliados conforme exposto no Quadro 1 e os resultados são apresentados na Tabela 1. A tabela sistematiza os resultados alcançados pelos alunos com a produção dos mapas por eles construídos. Após a realização do cálculo de cada aspecto avaliado foi efetuada a soma desses valores para obtenção do total de pontos alcançado pelo aluno.

Todos os alunos que participaram da construção do mapa conceitual conseguiram apresentar o conceito geral de citologia, algumas organelas, estruturas e suas respectivas funções. Percebeu-se, com isso, um avanço na aquisição de conceitos uma vez que, se comparados aos resultados da atividade avaliativa dos subsunçores, as questões que continham esses conteúdos foram as que obtiveram maior índice de erros na ocasião. Os mapas elaborados mostram que todos os alunos conseguiram reconhecer a existência de três tipos de células distintas, cada um deles conseguiu citar de pelo menos cinco estruturas e organelas, sendo que dois alunos conseguiram citar organelas específicas da célula vegetal, como o vacúolo e todos citaram estruturas da célula procarionte, como os flagelos. Nota-se que os alunos conseguiram fazer as relações entre as estruturas e organelas e suas funções.

Outro ponto positivo é que os alunos 
Tabela 1: aspectos avaliativos alcançados pelos alunos do Clube de Ciências da Escola Estadual Padre José Monticone resultantes da produção do mapa conceitual por eles construídos, os mesmos encontram-se identificados pelos números 1, 2, 3, e 4. Tabela adaptada de Freitas (2011).

\begin{tabular}{|c|c|c|c|c|}
\hline ALUNO & CRITÉRIOS A & $\overline{\mathrm{VOS}}$ & PONTOS & TOTAL PONTOS \\
\hline \multirow{6}{*}{1} & \multirow[t]{2}{*}{ RELAÇÕES } & $\begin{array}{l}\text { COM PALAVRA } \\
\text { DE LIGAÇÃO }\end{array}$ & $14 \times 2=28$ & \multirow{6}{*}{ 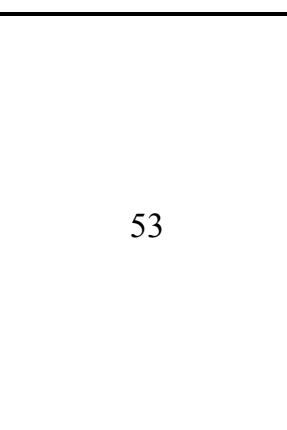 } \\
\hline & & $\begin{array}{l}\text { SEM PALAVRA } \\
\text { DE LIGAÇÃO }\end{array}$ & $0 \times 1=0$ & \\
\hline & HIERARQUIA & & $5 \times 5=25$ & \\
\hline & \multirow{3}{*}{$\begin{array}{l}\text { LIGAÇÕES } \\
\text { CRUZADAS }\end{array}$} & SIGNIFICATIVA & $0 \times 10=0$ & \\
\hline & & $\begin{array}{l}\text { NÃO } \\
\text { SIGNIFICATIVA }\end{array}$ & $0 \times 2=0$ & \\
\hline & & CRIATIVA & $0 \times 15=0$ & \\
\hline \multirow{6}{*}{2} & \multirow[t]{2}{*}{ RELAÇÕES } & $\begin{array}{l}\text { COM PALAVRA } \\
\text { DE LIGAÇÃO }\end{array}$ & $17 \times 2=34$ & \multirow{6}{*}{64} \\
\hline & & $\begin{array}{l}\text { SEM PALAVRA } \\
\text { DE LIGAÇÃO }\end{array}$ & $0 \times 1=0$ & \\
\hline & HIERARQUIA & & $6 \times 5=30$ & \\
\hline & \multirow{3}{*}{$\begin{array}{l}\text { LIGAÇÕES } \\
\text { CRUZADAS }\end{array}$} & SIGNIFICATIVA & $0 \times 10=0$ & \\
\hline & & $\begin{array}{l}\text { NÃO } \\
\text { SIGNIFICATIVA }\end{array}$ & $0 \times 2=0$ & \\
\hline & & CRIATIVA & $0 \times 15=0$ & \\
\hline \multirow{6}{*}{3} & \multirow[t]{2}{*}{ RELAÇÕES } & $\begin{array}{l}\text { COM PALAVRA } \\
\text { DE LIGAÇÃO }\end{array}$ & $7 \times 2=14$ & \multirow{6}{*}{41} \\
\hline & & $\begin{array}{l}\text { SEM PALAVRA } \\
\text { DE LIGAÇÃO }\end{array}$ & $7 \times 1=7$ & \\
\hline & HIERARQUIA & & $4 \times 5=25$ & \\
\hline & \multirow{3}{*}{$\begin{array}{l}\text { LIGAÇÕES } \\
\text { CRUZADAS }\end{array}$} & SIGNIFICATIVA & $0 \times 10=0$ & \\
\hline & & $\begin{array}{l}\text { NÃO } \\
\text { SIGNIFICATIVA }\end{array}$ & $0 \times 1=0$ & \\
\hline & & CRIATIVA & $0 \times 15=0$ & \\
\hline \multirow{6}{*}{4} & \multirow[t]{2}{*}{ RELAÇÕES } & $\begin{array}{l}\text { COM PALAVRA } \\
\text { DE LIGAÇÃO }\end{array}$ & $18 \times 2=36$ & \multirow{6}{*}{61} \\
\hline & & $\begin{array}{l}\text { SEM PALAVRA } \\
\text { DE LIGAÇÃO }\end{array}$ & $0 \times 1=0$ & \\
\hline & HIERARQUIA & & $5 \times 5=25$ & \\
\hline & \multirow{3}{*}{$\begin{array}{l}\text { LIGAÇÕES } \\
\text { CRUZADAS }\end{array}$} & SIGNIFICATIVA & $0 \times 10=0$ & \\
\hline & & $\begin{array}{l}\text { NÃO } \\
\text { SIGNIFICATIVA }\end{array}$ & $0 \times 2=0$ & \\
\hline & & CRIATIVA & $0 \times 15=0$ & \\
\hline
\end{tabular}

conseguiram desmembrar satisfatoriamente cada um dos tipos de células de maneira hierárquica, citando o ensino de citologia como aquele que estuda as células e que as células dividem-se em procariontes e eucariontes. Tratando-se dessa hierarquia, Moreira (2010, p.12) destaca que os mapas conceituais podem seguir um "modelo hierárquico no qual os conceitos mais inclusivos estão no topo da hierarquia (parte superior do mapa)" e os "conceitos específicos, pouco abrangentes, estão na base (parte inferior)" do mapa, como as estruturas e organelas respectivamente com algumas funções.

Além disso, Moreira (2010, p.15), destaca que na produção dos mapas conceituais

Não há regras gerais fixas para o traçado de mapas de conceitos. O importante é que o mapa seja um instrumento capaz de evidenciar significados atribuídos a conceitos e relações entre conceitos no contexto de um corpo de conhecimentos, de uma disciplina, de uma matéria de ensino. 
Moreira (2010) enfatiza que, mesmo os alunos seguindo as regras eles produzirão mapas com conceitos pessoais, que conterão semelhanças e diferenças entre os alunos, como nota-se na confecção dos mapas dos alunos do clube, onde alguns colocaram mais estruturas que outros.

Finalmente, foi aplicado um pequeno questionário contendo 04 questões cada uma com um objetivo específico, onde todos os alunos participantes do projeto responderam.

$\mathrm{Na}$ primeira pergunta solicitou-se que eles escrevessem um pouco sobre o que tinham aprendido no clube de Ciências. Nessa questão uma aluna respondeu que tinha aprendido que existem vários tipos de células, a animal, a vegetal e a da bactéria, que agora ela saberia diferenciar cada uma delas e que aprendeu ainda que dentro das células existem várias organelas com diferentes funções. Outra aluna respondeu que tinha aprendido muito sobre o "fabuloso mundo das células" e como cada uma delas funciona. A mesma aluna mencionou que observou e aprendeu cada pequena parte das células por meio das maquetes, ao final ela citou algumas organelas e estruturas celulares.

A segunda questão perguntava que nota eles dariam para o projeto, onde tinham as opções: ótimo, bom, regular, e ruim. As respostas foram unânimes que dariam ótimo.

$\mathrm{Na}$ terceira questão foi solicitado que os alunos indicassem entre as atividades do clube quais teriam mais gostado e que justificassem suas respostas. Cada aluna respondeu que gostou de uma atividade diferente: uma gostou mais dos mapas, outra gostou de produzir a célula vegetal, outra do jogo da memória e, a última, de construir as maquetes das células, por considerar interessante você conseguir ver e mostrar para outras pessoas o que tem dentro de uma célula. Nota-se que cada aluna gostou de uma atividade evidenciando a importância dos professores variarem as formas de trabalhar em sala de aula.

Segundo Rosa (2012), as aulas diferenciadas são importantes inovações para elevar o grau de motivação, estímulo e criatividade para gerar um ensino efetivo aos alunos. $\mathrm{O}$ motivo pelo qual a autora destaca a importância das aulas diferenciadas é que os alunos não aprendem da mesma forma, tornando assim, necessário que os professores busquem inovações, métodos mais apropriados e diferenciados para as aulas ministradas.
Por fim questionou-se o que eles levariam de aprendizado para o seu cotidiano. Dentre as respostas vale destacar a aluna que mencionou que aprendeu que existem várias maneiras de aprender e que ela aprendeu que coisas pequenas fazem toda a diferença.

Assim, o Clube de Ciências busca estimular nos participantes esse olhar de que existem várias maneiras de aprender, segundo Santos (2008), os Clubes de Ciências proporcionam momentos e locais diferenciados para os alunos extrapolarem o domínio escolar quando se trata de aprender com prazer. Assim o clube proporciona por meio das atividades diferenciadas a motivação para a busca pelo conhecimento, considerado um importante passo para que a aprendizagem seja significativa.

\section{CONSIDERAÇÕES FINAIS}

A primeira etapa da presente pesquisa mostrou, por meio da análise dos subsunçores dos estudantes, realizada com o auxílio do um software criado pelos alunos do mestrado da Universidade Estadual de Roraima, que os alunos participantes do clube apresentavam conhecimentos mais gerais, mais inclusivos, referentes ao conteúdo de Citologia.

Por meio do software foi identificado que os alunos tinham mais subsunçores para a atividade 1 onde solicitou-se que respondessem perguntas gerais sobre os diferentes tipos de células. A maioria dos alunos apresentou dificuldade nas organelas e suas funções, solicitadas na atividade 2, devido ao fato de ainda não terem estudado detalhadamente $\mathrm{o}$ conteúdo.

A partir dos resultados obtidos na análise dos subsunçores foram elaboradas e selecionadas atividades didáticas, através de jogos, filmes, aulas com microscópio e confecção de lâminas para visualizar organelas e estruturas celulares, modelos celulares, aulas de campo, sendo que tais ferramentas foram potencialmente significativas para a aprendizagem dos alunos. Assim, nessa etapa da teoria da aprendizagem significativa trabalhou-se a aquisição e a retenção do novo conhecimento.

Posteriormente foi aplicada como forma de avaliação, a construção de mapas conceituais, realizado pelos alunos individualmente, onde ficou notória a aprendizagem dos alunos, pois 
conseguiram apresentar o conceito geral de citologia, tipos de células, algumas organelas, estruturas e suas respectivas funções, demonstrando que as atividades trabalhadas foram significativas para a aprendizagem dos alunos.

Por fim foi aplicado um questionário opinativo para verificar o grau de aceitação das atividades e do Clube de Ciências pelos membros participantes, as respostas foram unânimes ao afirmar que acharam ótimo participar do clube, que aprenderam muito com as atividades desenvolvidas e que o clube proporcionou experiências que levarão para $o$ seu cotidiano.

\section{REFERÊNCIAS BIBLIOGRÁFICAS}

Antunes, C. 2001. Como transformar informações em conhecimento. Petrópolis, Vozes.

Ausubel, D.P. 2003. Aquisição e Retenção de Conhecimentos: Uma Perspectiva Cognitiva. $1^{\mathrm{a}}$ edição. Ed.: Plátano edições técnicas.

Barbiere, M.R. 2002. Laboratório de ensino de ciências. 20 anos de história. Ribeirão Preto. Ed. Holos.

Borges, R.M.R. \& Moraes, R. 1998. Educação em ciências nas séries iniciais. Porto Alegre. Sagra Luzzatto.

Brandão, C. 2015. O uso de modelos e maquetes no ensino de ciências. Disponível em: http:// webcache.googleusercontent.com/. Acessado em: $18 / 02 / 2015$

Brasil. 1998. Parâmetros curriculares nacionais (Ensino Médio). Parte III: Ciências da Natureza, Matemática e suas Tecnologias. Brasília.

Calluf, C.C.H. 2007. Didática e Avaliação em Biologia. 1. ed. Curitiba.Ibpex.

Delizoicov, D. 2007. Ensino de Ciências: fundamentos e métodos. 2. ed. São Paulo: Cortez.

Felicio, D.L.A. et al. 2013. Reativação de Laboratórios de Química de Escolas na Região Metropolitana de João Pessoa-PB. Revista Atas do IX Encontro Nacional de Pesquisa em Educação em Ciências IX ENPEC Águas de Lindóia, SP - 10 a 14 de Novembro de 2013.

Fernandes, K.B. et al. 2014. Diálogos entre professores da educação básica na criação de um "clube de ciências". Rio de Janeiro/RJ.

Fialho, N. N. 2007. Jogos no Ensino de Química e Biologia. 2. ed. Curitiba. Ibpex.

Freitas, M.S.S. 2011. Práticas Didáticas Alternativas nas Aulas de Ciências do $6^{\circ}$ ano da Escola Estadual Antônio Nascimento Filho. Monografia (Ciências Biológicas) - Universidade Estadual de Roraima, Mucajaí, Roraima. 94p.

Godefroid, R.S. 2010. O Ensino de biologia e o cotidiano. 1. Ed. Curitiba. Ibpex.

Guimarães, L. R. 2009. Atividades para as aulas de ciências: Ensino fundamental $6^{\circ}$ ao $9^{\circ}$ ano. São Paulo: Nova Espiral.

Grein, A.C.V. et al. 2014. Aprendendo Ciências em Clube de Ciências. Paraná.

Krasilchik, M. 2004. O professor e o currículo das Ciências. São Paulo: EPU; EDUSP.

Kishimoto, T. M. (Org.). 2002. Jogos, brinquedos, brincadeira e a educação. 6 ed. São Paulo: Cortez.

Martinelli, M.L. (org.). 1999. Pesquisa qualitativa: um instigante desafio. Ed. Veras: São Paulo.

Martins, R. 2015. Disponível em: http:// nogueirense.com.br/voluntarios-fazem-mutirao-parapintar-escola-em-artur-nogueira/. Acessado em: $13 / 03 / 2015$.

Menezes, C. 2012. Clubes de Ciências: contribuições para a educação científica nas escolas da Rede Municipal de Ensino de Blumenau - SC. 2012. Dissertação (Mestrado). Universidade Regional de Blumenau, Blumenau.

Moreira, M. A. 2010. Mapas conceituais e aprendizagem significativa. $1^{\text {a }}$ ed. São Paulo. Centauro.

Moreira, M. A. \& Masini, E. F. S. 2001. Aprendizagem Significativa: a teoria de David Ausubel. São Paulo: Centauro.

Novak, J. 1984. Aprender a aprender. Lisboa: Paralelo.

Pelizzari, A. et al. 2002. Teoria da aprendizagem significativa segundo Ausubel. Curitiba.

Rosa, A. B. 2012. Aula diferenciada e seus efeitos na aprendizagem dos alunos: O que os professores de Biologia têm a dizer sobre isso? Porto Alegre.

Santos, J.C.F. 2008. O papel do professor na promoção da aprendizagem significativa. Revista UNIABEU Educação e Saúde 1: 9-14.

Santos, D.J. F. 2008. Guia de orientações para implementação de um clube de ciências. São Paulo.

Santos, S. et al. 2010. Confecção e utilização de modelagem didática, a partir de massa de modelar, no ensino de células- tronco. Recife: [s.n.].

Silva, C.X. 2009. A experiência do ensino blocado em LONDRINA-PR e os recursos didáticos utilizados em sala de aula: a adaptação dos professores a esta nova organização da estrutura das aulas. Universidade de Londrina Paraná.

Silva, J. B. \& Borges, C.P.F. 2009. Clubes de Ciências como ambiente de formação profissional de professores. Curitiba.

Souza, E.O.S. et al. 2004. Projeto de reorientação curricular para o estado do Rio de Janeiro ensinos médio e fundamental (2.segmento). Rio de Janeiro.

Ward, H. et al. 2010. Ensino de Ciências. Tradução Ronaldo Cataldo Costa; consultoria e revisão técnica desta edição José Fernando Bitencourt Lomônaco. Porto Alegre: Artmed. 